\title{
A Study on Old Havelis: Lost Heritage of Saharanpur
}

\author{
Aayushi Verma', Prof. Ila Gupta ${ }^{2}$ \\ ${ }^{1}$ Department of Humanities and Social Science, Indian Institute of Technology, Roorkee, \\ Uttrakhand, India, 247667. Email: ayushiozverma@gmail.com \\ ${ }^{2}$ Department of Architecture and Planning, Indian Institute of Technology Roorkee, \\ Uttrakhand, India, 247667
}

\begin{abstract}
From centuries, our tangible and intangible cultural heritage is considered as an inspiration for life which passes down from one generation to the next. Cultural heritage has its value and place in the heart of society. In cultural heritage, architecture is a showcase of our rich tradition which is our legacy from the past to the present world. Concerning this, Saharanpur is internationally famous for wood carving and closely associated with the socio-economic life of the district. These particular art forms have evolved for centuries as an inseparable and intimate part of its culture. Moreover, the other significant feature of Saharanpur is old havelis (mansions) which were constructed with imperial influence. Old havelis of Saharanpur demonstrate the glimpse of Mughal art and architecture, a characteristic Indo-Islamic-Persian style. Gradually, old havelis of Saharanpur are slowly losing its authenticity due to unawareness of people and their lack of knowledge about the cultural ethos which is attached to it. The art and crafts of these havelis are slowly fading away due to lack of proper infrastructure and initiatives for maintenance. Government has not yet taken enthusiasm for protection against slow demolition of this cultural heritage. Therefore, most of the havelis of this area have torpedoed and rests of the old havelis are on verge of vanishing. Hence, government must take preventive measures and initiatives for restoration and preservation of these havelis. The aim of heritage conservation is to ensure that the cultural significance of heritage places is retained for future generations. This paper makes an effort to create an overview of the architectural heritage buildings (havelis) of Saharanpur and highlights the certain recommendations for safeguarding these old havelis.
\end{abstract}

Keywords: Haveli, Saharanpur, Cultural Heritage, Conservation

\section{Introduction}

"Heritage" is a broad concept which includes the culture, historic places, sites, landscapes as well as architecture. Architecture is not merely the concrete form of bricks and cement but also a visual representation of aesthetic, artistic and cultural expression which has remarkable aspects of beautifying the society. We need to understand the decorative elements of architecture with rich details. The sense of beautification and aesthetics has developed with the passage of time and expanded with innovation of designs, techniques, and materials. Decoration is an enchanting process of art domain that renders the exteriors and interiors more attractive and ornate. In architecture, exterior and interior decoration have very significant role and considered two sides

(C) AesthetixMS 2017. This Open Access article is published under a Creative Commons Attribution Non-Commercial 4.0 International License (http://creativecommons.org/licenses/by-nc/4.o/), which permits non-commercial re-use, distribution, and reproduction in any medium, provided the original work is properly cited. For citation use the DOI. For commercial re-use, please contact editor@chitrolekha.com 
of one coin. In this context, exterior decoration is the façade of architecture which influences the viewers and creates negative and positive vibes. Sometimes it presents welcoming effect and sometimes it produces a repellant picture. It depends on sentiments, which are based on visual elements and decorations of architecture. For instance, vernacular architecture is the pictorial representation of local needs, environment, economy, and culture which evoke the sentiments of viewers. In addition, exterior expression of architecture can be reflected through mural paintings and wood carving which are strongly associated with cultural values. Concerning this, wall paintings have been traced from ancient time. Here, the authors serve the discussion on wall paintings because there is requirement to explain mural painting. In Latin language, 'mural' word denotes murus which means 'wall'. Painting is a creative expression and preparation of applying color and paint on surface. Any kind of work done on walls is called mural. A mural is a technique of art to paint or apply color directly on wall, ceiling and other permanent surface with specially prepared plastered surface. "Wall paintings are pictures that have been painted directly on the surface of wall which cannot be moved" (Pappalardo, 2009). Mural painting can be fundamentally classified as fresco, encaustic, oil and tempera paintings. Fresco is done on wall and ceiling with freshly laid or wet lime plaster. In Italian language, the word 'fresco' means affresco which means 'fresh'. Adams (1999) refers to murals as fresco and explains that a mural can be applied to and made integral part of the surface of a wall, ceiling or floor. Mural is an aesthetic manifestation of architecture which throws light on its embellishment. In this regard, old havelis of Saharanpur display the exterior decoration through mural painting in which fresco technique have been adopted for artistic harmony that break the boring ambience of artless exterior by creating artistic manner (Jain, 2011). These havelis are prominent for frescoes depicting images of animals, birds, plants and figurative images (fig.1, 2). These havelis somehow bring back the memories of the Mughals. These havelis are the representative of past which have become superseded today.

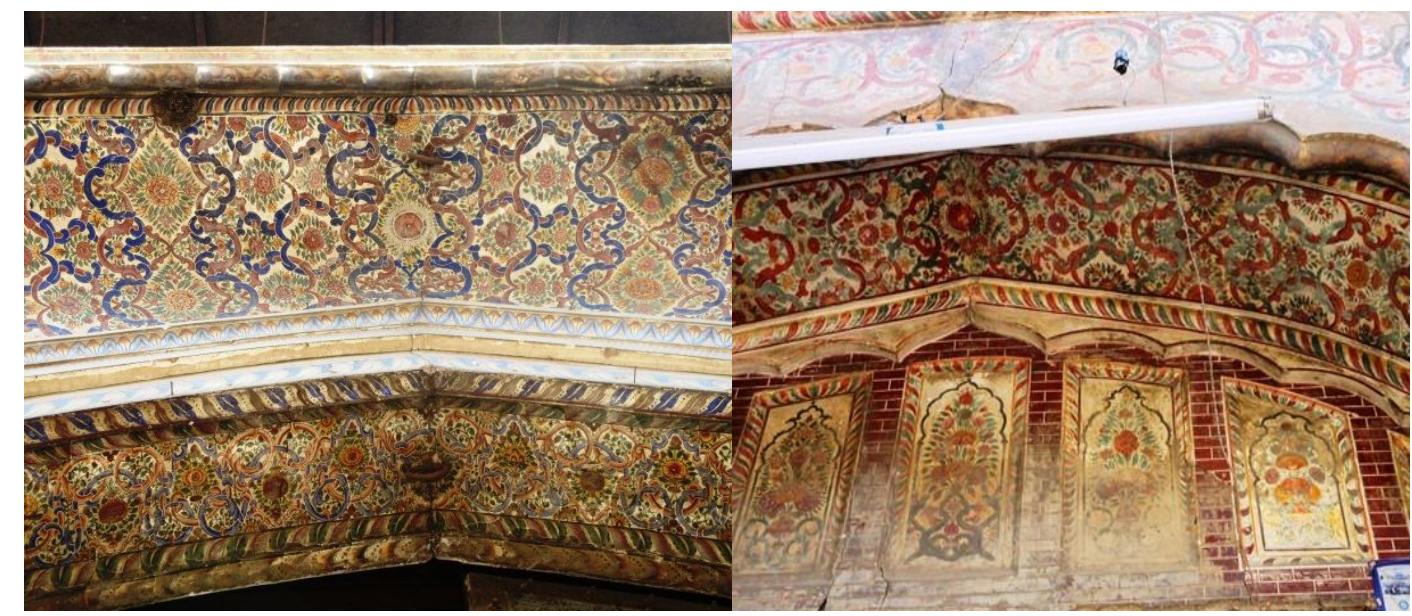

Figure:1 Mural Painting on Haveli of Aatma Ram in Dina Nath Bazar

Figure:2 Mural Painting on Haveli in Chhatta Jambudas

Source: Authors

Additionally, old havelis of Saharanpur demonstrate artistic treatment of ornamentation through wood or stone carving which has become a part of cultural heritage in this region. In the context of wood carving, wood has been considered as a medium of livelihood and artistic consideration in which artisans develop many ideas of creativeness through carving and enhance the importance of wood. During the long periods between 2500 to 1500 B.C. and about 250 B.C. (when architecture began to appear in stone), wood certainly served most purposes for living accommodation, in the places of worship, and in the building of monuments, as well as for many 
varied articles of utility and decoration (Pramar, 1989). The application of wood in architecture can be seen through doors, door frame, windows, and brackets and so on which is appreciable. On the other hand, the tradition of stone carving existed in India a little as compared to wood carving. Earliest monuments of India are the excellent example of stone carving which can be seen through windows, door frames, brackets and few others. In this regards, in Uttar Pradesh, Saharanpur is very prominent city for wood carving. The old havelis of Saharanpur city got attention through wood carving and stone carving, in which very prominent designs has been adopted as an ornamentation of havelis. These havelis reveal a story behind the adoption of designs and create an eye catching view. Today, these havelis are best surviving example of our past heritage and become an essential part of society which cannot be separated from our culture and society. Apart from certain traditional decorative features, these havelis have their own architectural identity which may not be denied. This paper discusses the significance of havelis because these are like imprints of people which get transmitted from one generation to another. Thus, it is much needed to spread awareness about the architectural identities and its importance in our lives and societies.

\section{Purpose of Study}

Old havelis of Saharanpur have expressed ample evidence of its existence, but there is no proper documentation available in written, printed, photographed or other forms, which may provide a systematic understanding of these havelis. These havelis are an approximately 150-300 years old heritage and became the important part of daily life. So it's essential to evaluate and compile it in textual record, which may reveal the artistic mysteries of these havelis for better understanding of the viewer. The purpose of this study is to make an overview to these old havelis of Saharanpur and evaluate them and create awareness in people to protect them.

\section{Research Methodology}

For this paper, four havelis have been selected for discussion and results: Haveli in Chhatta Jambudas (fig.3), Haveli in Bartala Yadgar (fig.4), Haveli of Aatma Ram in Deena Nath Bazar (fig.5) and one more Haveli in Chhatta Jambudas (fig.6). The information has been collected from the owners of these havelis as well as localites and neighbors. The data and information on age, condition, and present use; historical, architectural, and cultural aspects along with the visual analysis of each of havelis have been collected in the field study.
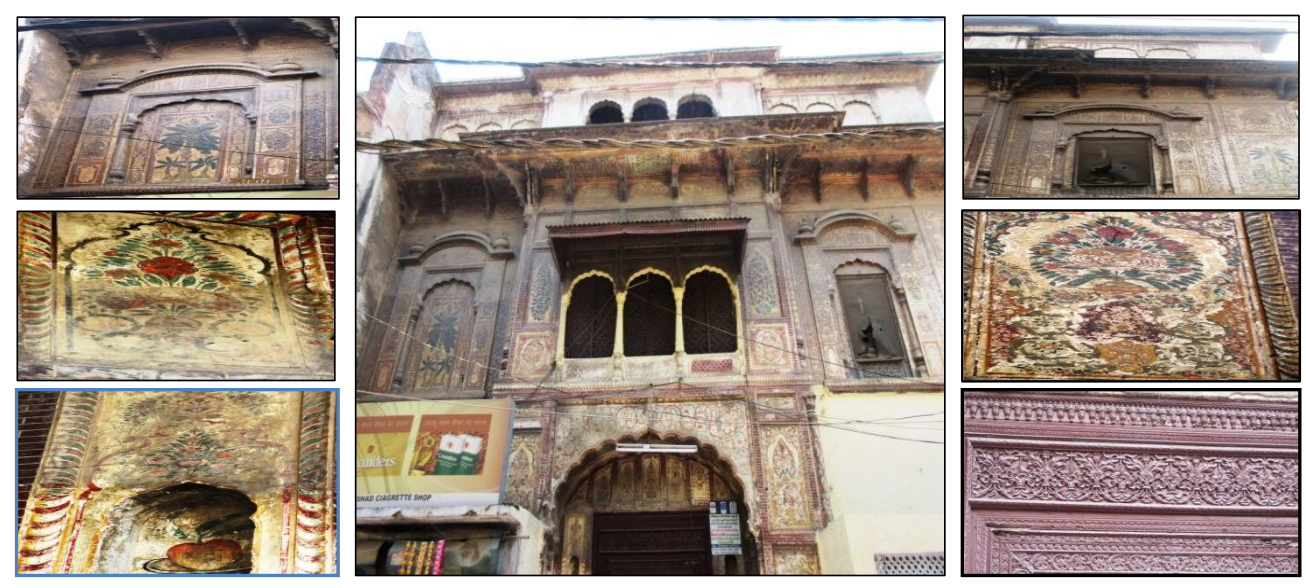

Figure:3 An orante Haveli in Chhatta Jambudas 
5 | Chitrolekha Journal on Art and Design, Vol. 1, No. 1, 2017

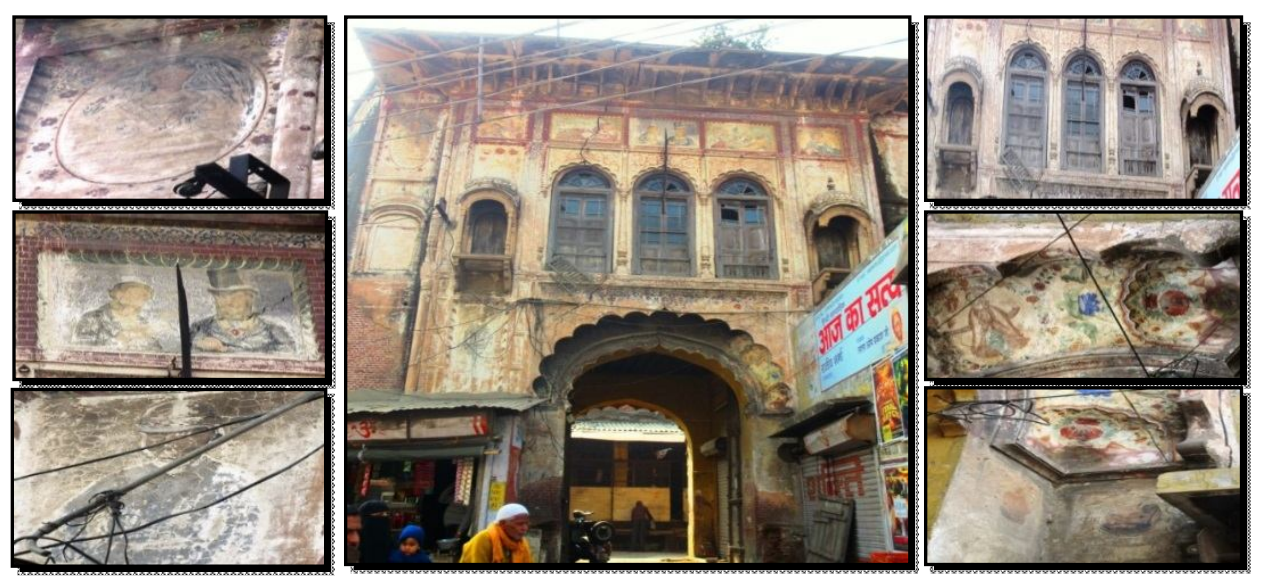

Figure:4 An orante Haveli in Bartala Yadgar
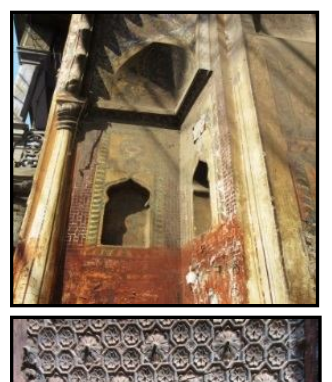

20,

1.20.9.2.

F.7. 7.6 .

$x+2.010$

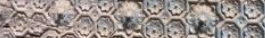

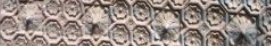
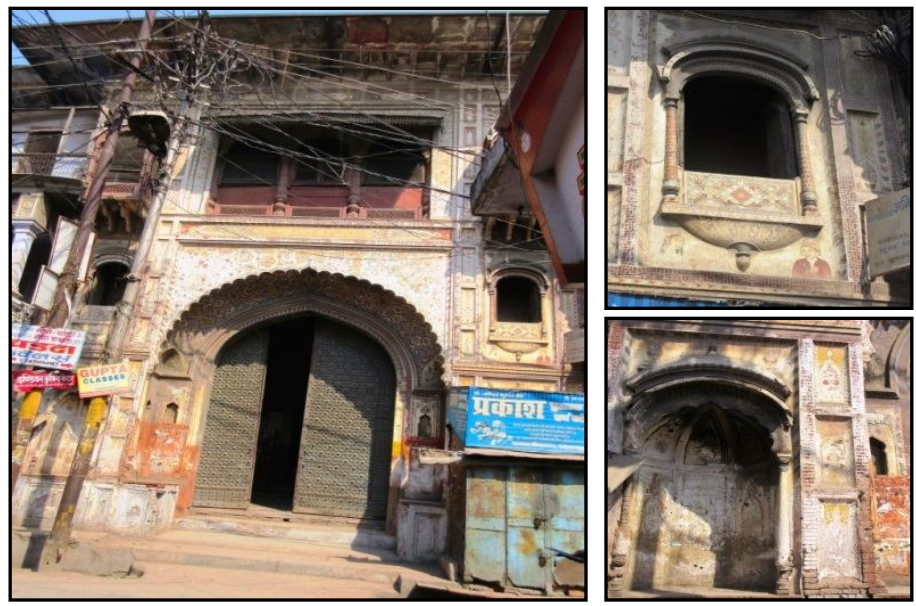

Figure:5 An orante Haveli of Aatma Ram in Dena Nath Bazar
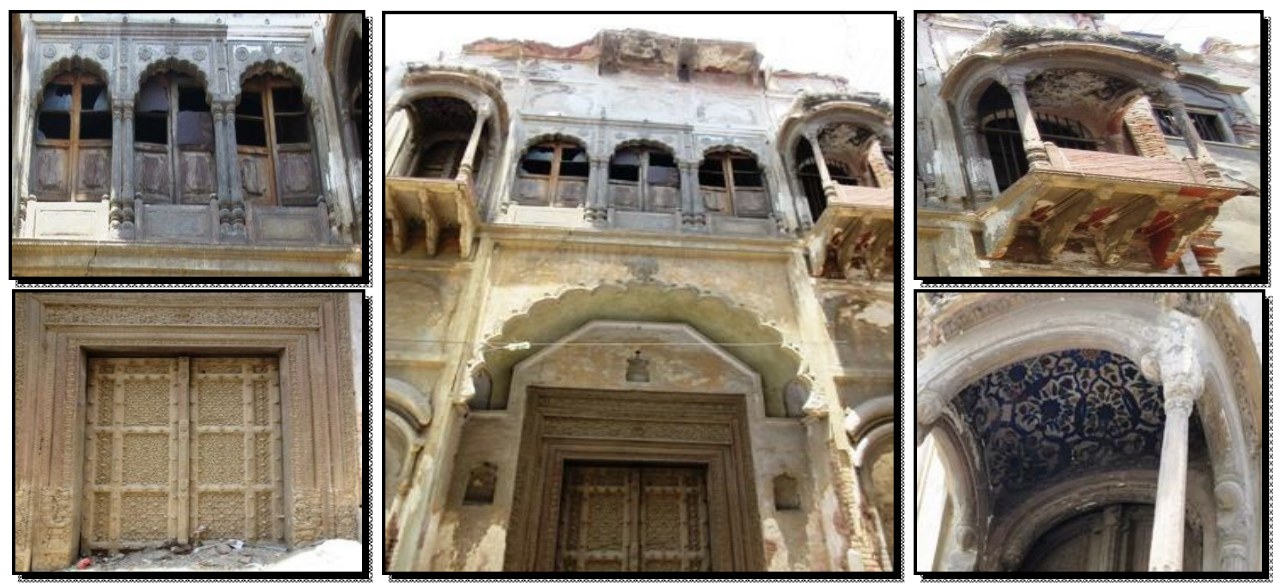

Figure:6 An orante Haveli in Chhatta Jambudas Source: Author 


\section{Study Site}

Saharanpur district is situated between the Ganga-Jamuna doab region is known as one of the major district of the state of Uttar Pradesh, in northern India and got its name from the name of Sufi saint 'Shah Harun Chisti' in the $13^{\text {th }}$ century. Moreover, Saharanpur came in prominence under the Mughal dynasty and developed with rapid pace of time and became the administrative hub and summer resort. Saharanpur was a small village before the time of Akbar (the Mughal emperor), who was first to notice Saharanpur (Jain, 2000; Jain, 2011).During the Mughal period, wood carving center- anew event was announced in the history of Saharanpur. At the time of Mughal dynasty, some craftsmen families came from Kashmir and settled in Saharanpur for sustenance and livelihood. At this time, some of the best havelis were built during the tenure of Mughal governors of Saharanpur- Shah Ranbir Singh and Muhammad Bakka. Shah Ranbir Singh belonged to wealthy Jain community and invited the Jain trading people to settle their business in Saharanpur (Jain, 200o). Therefore, Jain families were settled in Saharanpur and constructed their havelis and chhattas. It was the main reason that most of the renowned havelis in this area were built by Jain community. Another eminent governor of Saharanpur under the Mughals was Muhammad Bakka who was known to have built many havelis, mosques and dug many wells. The Mughal dynasty under Akbar till Aurangzeb left a lifelong impression on culture and the cuisine of the area. For Instance, Mughal influence can be easily traced in this area through architectural style and design elements which were so prevalent during this era such as projected balconies, intricate lattice work and cusped arches. Cusped arches are a feature ubiquitous to Saharanpur. They were introduced by the Mughal and have been widespread ever since. All the entrance doors were usually set in a cusped arch. Even the newer buildings had tried to retain this feature. Additionally, the Mughal concept of town planning and architecture is was also clearly visible in Saharanpur which reminded us of the imperial era of the great Mughals.

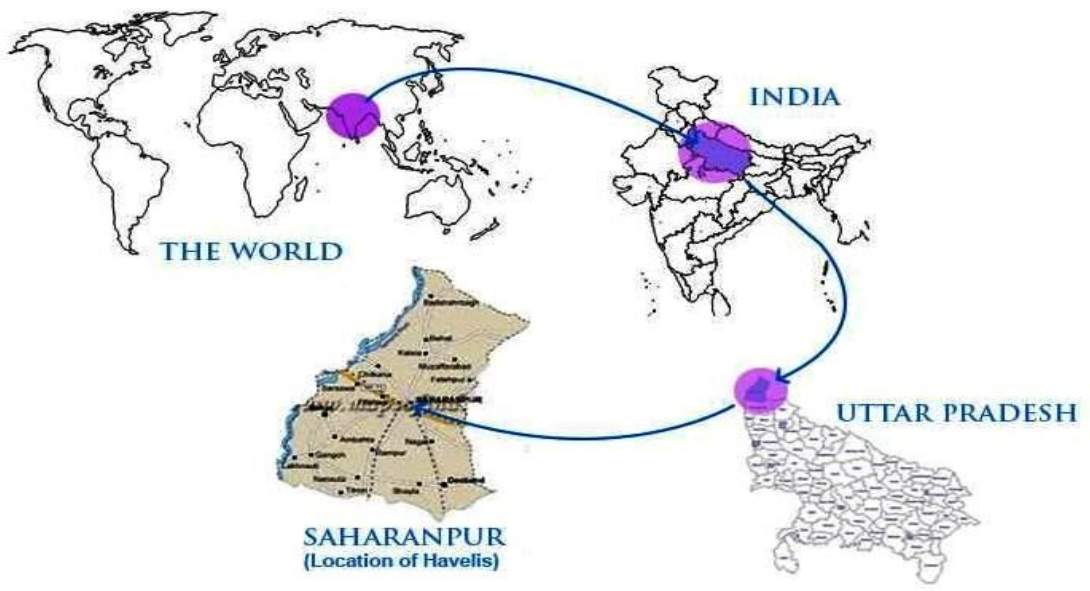

Figure:7 Location of Havelis on a World Map Source: Authors

\section{Concept of Haveli}

The term haveli is commonly used for a traditional large mansion with historical and architectural significance that flourished during the $18^{\text {th }}$ and $19^{\text {th }}$ century particularly in Rajasthan and Gujarat. "The word haveli was derived from Arabic haveli, meaning "private space" which was popularised under Mughal era" (Tillotson,1998 ;Haveli,2016).Historically a haveli was the (visual) representation (and social status/symbol) of prestige of the owner which expressed goodwill 
(reputation) of the owner in society. Haveli was considered to be signifying the economic status of the owner. The Haveli displayed high ornate walls with frescos which demonstrated exquisite examples of craftsmanship and art. Frescos are often found decorating the walls of a haveli which attracts visitors. The other prominent feature of haveli was wood/stone carving on projected balconies, doors, and door frames painstakingly crafted by artists.

\section{Previous Efforts of Maintenance for Havelis}

As aforementioned, architectural buildings play a significance role in society. During the scheduled interview the study is found that being a part of cultural heritage, these havelis had been neglected by owners, because while talking to them, they said that they neither had sufficient money nor time to restore the haveli. Moreover, these havelis had been repainted (temporary treatment) sometime back with cheap material. Due to temporary treatment, these havelis have lost their originality and royalty. For temporary treatment, local and impermanent material has been used for the maintenance of havelis which was not suitable as per the climatic condition. Therefore, the façade of havelis has become lifeless and gloomy. With the passage of time, nuclear families have prevailed over joint families that evidently provide flexibility in everybody's life style and enough freedom of choice. Hence, gradually the concept of living in a Haveli has become obsolete and the popularity of Haveli architecture is retarded.

\section{Growing Need for Preservation}

Today, we are living in modern era where people's priority has changed according to technology shifts. Additionally, people are going to be self-centered and disconnected from customs, religion and social values which are the indication of heavy loss of humanity. Culture has a connection with the society in which people get attached to certain social values, beliefs, religions and customs. Herein, heritage buildings are the part of culture and cultural heritage can provide an automatic sense of unity and belonging within a group that allow us to understand previous generations better and the history of where we come from (Earl, \& Saint, 2015; Vecco, 2010). The architecture of these different buildings provides an aesthetic value to the society. Hence, localites should make an effort to maintain and value the heritage of those buildings (fig.8).

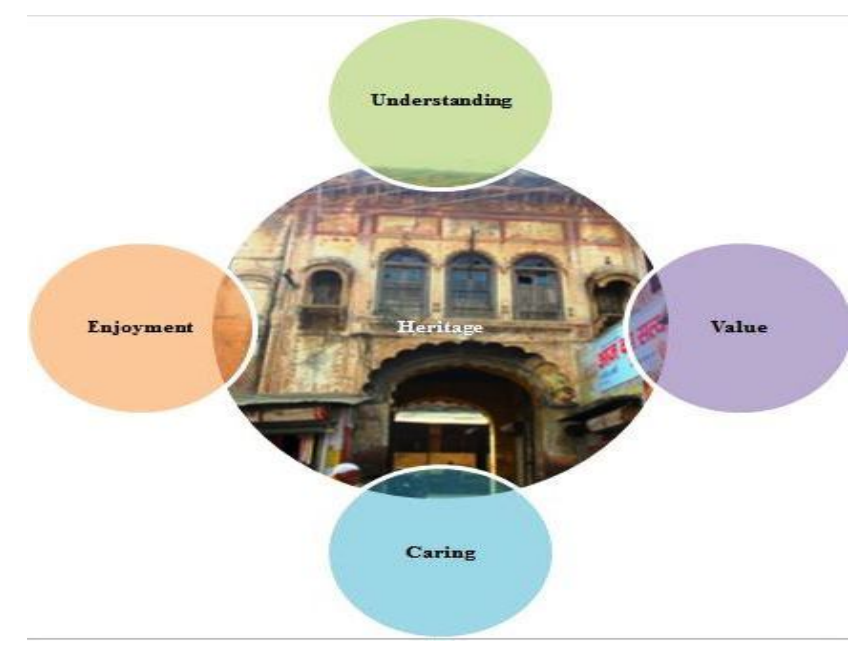

Figure: 8. The Heritage Cycle Diagram Source: Authors 
In the context of old havelis of Saharanpur, people do not have enough understanding of these significant buildings which were constructed in a particular time period and presently that type of architecture may not be found easily. For instance, in Chhatta Jambudas, two ornate havelis could be traced in which one was almost demolished and another one was converted to a ceremony hall. The former havelis sold by owner to make shops was later being given on rent for micro parties. Due to parties, the structure was damaged by visitors through different activities like spitting on walls and marks of wiping of dirty hands, etc. Other than this, garbage disposal is a common practice in front of these havelis. On the other hand, Haveli of Aatma Ram in Deena Nath Bazar has been given on rent for residential purposes by the owner. Thus day by day the structure of this haveli is getting distorted. Being located in commercialized and populated areas, all these havelis are being misused by local people, for instance by businessmen who cannot afford shops in malls make their stalls (food and others), thela and kiosks in front of these havelis. Excessive hoarding are also destroying the façade of havelis. Whereas, people should protect heritage buildings because heritage buildings are considered as treasure for us given by our forefather. The front of havelis is being destroyed by mesh of electrical wires overhead which is very unsafe while raining season. Another haveli located in Bartala Yadgar was a victim of ignorance. The beautiful haveli in Bartala Yadgar reminded us of the British rule. This haveli was the amply evidence of amalgamation of Mughal, British and Indian art. The structure of this haveli was influenced by the Mughal architecture; the mural in it revealed the image of a British and orientation of floral geometrical patterns were adorning the entrance. Unfortunately, this haveli was situated in market in an unfriendly environment. For instance, this haveli was divided as a residential property between two brothers in which one brother had sold his portion to make shops. On ground floor there was a grocery shop and first floor was given on rental basis for residential purposes. The condition of this haveli was very bad and the terrace of haveli was almost damaged. Gradually, the façade of havelis were spoiled due to unplanned parking of vehicles. Thus, it becomes important to safeguard these havelis because the architecture of havelis were very attractive and unique that had a historical value.

\section{Suggestions}

From the centuries, the 'havelis' were extensively used by the monarchs as well as wealthy people for the showcase of their goodwill and daily needs. But with changing times and subsequent variations in the lifestyle of the masses, these havelis have lost their importance in their lives. Based on the study of the behavioral patterns of people, we can identify certain prevailing factors due to which the usability of havelis has been reduced over a period of time.

These factors are:

- Unplanned market (where these havelis are situated)

- Lack of awareness and maintenance

- Mismanagement of crowd

- Parking issues

The above problems can be tackled by proposing a suitable design and layout of the concerned area. We also need to conserve the cultural heritage with proper maintenance and beautification of the havelis so as to enhance the long term value of the place. Government should take initiatives to spread the awareness in people through various channels like social media, advertisements, movies and workshops and seminars. By awareness, people will enjoy and protect their buildings for future generation. The mismanagement of crowd and parking issues can be tackled by planned market. For instance, Garbage bins should be sufficiently provided for and at 
appropriate locations which can cater to the entire marketplace. Age old overhead electrical wiring should be replaced with underground wiring. This will not only enhance the visual appeal of the place, but also prevents hazards. Unnecessary hoardings, banners, and advertisements should be removed from front of the havelis so that the actual historical façade may truly express itself. Old and Shabby havelis facades and walls with graphiti should be repainted with high quality material to match the overall character of the place.

\section{Conclusion}

It can be concluded that Saharanpur has got attention of viewers through wood craving as well as haveli architecture. Despite gaining attention these havelis had been found in unsatisfactory condition and the charm of these havelis was being degraded. As it has mentioned above, that people of Saharanpur was responsible for all damage of old building of Saharanpur. Misuse of old buildings and lack of conservation and maintenance are creating certain issues regarding environmental damage. Thus, there is need to rejuvenate all heritage buildings in this area. People should take initiatives individually to protect these heritage buildings and should create healthy environmental around them.

\section{Funding}

The paper got no funding for publication.

\section{References}

Adams, L. S. (1990). Art Across Time - Prehistoric to the Fourteenth Century. Volume 1 New York: McGrawHill, Inc.

Earl, J., \& Saint, A. (2015). Building conservation philosophy. Routledge.

Haveli. (2016, November 7). In Wikipedia, The Free Encyclopedia. Retrieved 18:56, November 7, 2016, from https://en.wikipedia.org/w/index.php?title=Haveli\&oldid $=748340995$

Jain, D. M. (2011). Jain Wall Painting in Doab Region: With Special Reference to Saharanpur and Adjoining Areas. Indus Publishing Company.

Jain, M. (2000). Wood handicraft: a study of its origin and development in Saharanpur. Indus Publishing.

Navrud, S., \& Ready, R. C. (Eds.). (2002). Valuing cultural heritage: applying environmental valuation techniques to historic buildings, monuments and artifacts. Edward Elgar Publishing.

Pappalardo, U. (2009). The Splendor of Roman Wall Painting. Getty Publications.

Pramar, V. S. (1989). Haveli: wooden houses and mansions of Gujarat. Mapin Publishing Pvt. Ltd..

Swamy, C. (2015). Planning for conservation of heritage areas in Mysore City.

Tillotson, S. (1998). Indian mansions: A social history of the haveli. Orient Blackswan.

Vecco, M. (2010). A definition of cultural heritage: From the tangible to the intangible. Journal of Cultural Heritage, 11(3), 321-324. 